\title{
Modification of Hydroxamic Acid Containing Compounds for Improved Metal Chelation
}

Karan Arora, ${ }^{1}$ Lamarque Coke, ${ }^{1}$ Earl Benjamin III, and Ellis Benjamin ${ }^{1}$

${ }^{1}$ Chemistry Program, NAMS, Stockton University, 101 Vera King Farris Drive, Galloway, NJ 08205-9441

Abstract: Hydroxamic acids (HXA) are functional groups with the ability to strongly chelate metal ions found in the reaction centers of biologically important proteins including that of Tumor Necrosis Factor $\alpha$ Converting Enzyme (TACE)/(ADAM-17). These hydroxamic acids are able to inhibit the enzymatic activities that are necessary for the normal progression of diseases such as HIV and cancer. One example is hydroxamic acids ability to block the release of the TNF $\alpha$ into the bloodstream of cancer and HIV patients thereby decreasing the inflammation response and slowing disease progression. This work sought to understand what modification surrounding the hydroxamic acid would be able to increase the overall binding affinity for metal chelation. Differences in the inductive effects that surround the acids will be explored using ab-initio energy (DFT-B3LYP-631++G, and DFT-B3LYP-321-G) changes between apo/metal chelated molecules. These differences will seek to determine the best structural modification for improved hydroxamic acid design.

Introduction:

This research is to investigate the interaction of modified hydroxamic acids to determine specific metal chelation interactions. Hydroxamic acids are important moieties in the binding of Zinc metal in the active site of proteins necessary for cell proliferation including that of the TNF $\alpha$ Converting Enzyme (TACE) or ADAM17. TACE is a protein that cleaves membrane bound TNF $\alpha$ into the soluble form allowing for increased inflammation response in the region of cellular damage. The removal of the Zinc metal blocks the inflammatory response thereby slowing many disease progression. Many diseases including Alzheimer's disease and cancer progression increases in the presence of an inflammatory response. Through the use of modified hydroxamic acid we sought to understanding the metal chelation.<smiles>[R]C(=O)NO</smiles>

Figure 1. Hydroxamic Acid (HXA)

Hydroxamic acid chelation normally binds in a bidentate configuration between the carbonyl and the hydroxyl group of the hydroxamic acid (Figure 2). Difference between the binding energies of the hydroxamic acids can determine the overall stability of the metal chelation. This can be calculated by using the $\Delta G$ with the products being the Zinc bound HXA and the reactant being the apo HXA and the Zinc metal. 


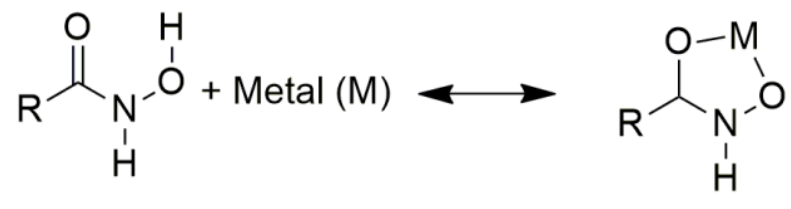

Apo HXA

Metal Bound HXA

Figure 2. Metal Binding of Hydroxamic Acid (HXA)

Specific Aims:

This research sought to use hydroxamic acid as a model to understanding Zinc chelation:

1. The interaction of electron withdrawing group length on the interaction of the HXA.

2. The interaction of electron donating group length on the interaction of the HXA.

3. The energy effects of electron withdrawing groups (EWG) on hydroxamic acids.

4. The energy effects of electron donating groups (EDG) on hydroxamic acids.

5. The trends found with the inclusion of halogens.

Experimental Design:

Molecules were designed in Cambridgesoft ChemDraw and minimized using MM2 in Chem3D. Ab initio calculation were done using Gaussian. The method used a Ground State DFT B3LYP with the base set $631++G$. With the exception lodo derivative being DFT B3LYP with the base set 321G. (Data was recorded in au units and then converted to $\mathrm{Kcal} / \mathrm{mol}$ (multiplied by 627.52))

1. The Bonding of Apo Hydroxamic acid vs Zinc Bound Hydroxamic Acid.

This experimental data determines the energy for the binding of the metal to the hydroxamic acid. It is calculated by: $\Delta \mathrm{G}=\Sigma$ (Products - Reactants)

$$
\Delta G=\Sigma((\text { Metal Bound HXA })-(\text { Apo HXA }+ \text { Metal }))
$$

2. The average energy interactions based on EDG length, EWG length, and Halogens.

$$
\text { Average Energy }=((\text { Apo HXA })+(\text { Metal Bound HXA })) / 2
$$

3. The trends of EWG length, EDG length, and Halogen were calculated using MS Excel.

4. The overall stabilization energy was calculated by the average energy of the molecule vs the standard hydroxamic acid (show below).

\section{Standard Hydroxamic Acid}<smiles>O=CNO</smiles> 
Results:

Electron Withdrawing Group (Length)<smiles>O=C(NO)C(F)(F)F</smiles>

1<smiles>O=C(CC(F)(F)F)NO</smiles>

2<smiles>O=C(CCC(F)(F)F)NO</smiles>

3<smiles>O=C(CCCC(F)(F)F)NO</smiles>

4<smiles>O=C(CCCCC(F)(F)F)NO</smiles>

5

\begin{tabular}{c|c} 
Molecule & $\Delta G$ (EWG length) \\
\hline 1 & 10.7268 \\
2 & 11.7611 \\
3 & 11.3544 \\
4 & 11.1716 \\
5 & 11.4825 \\
\multicolumn{2}{|c|}{ Average 11.299 (0.385) }
\end{tabular}

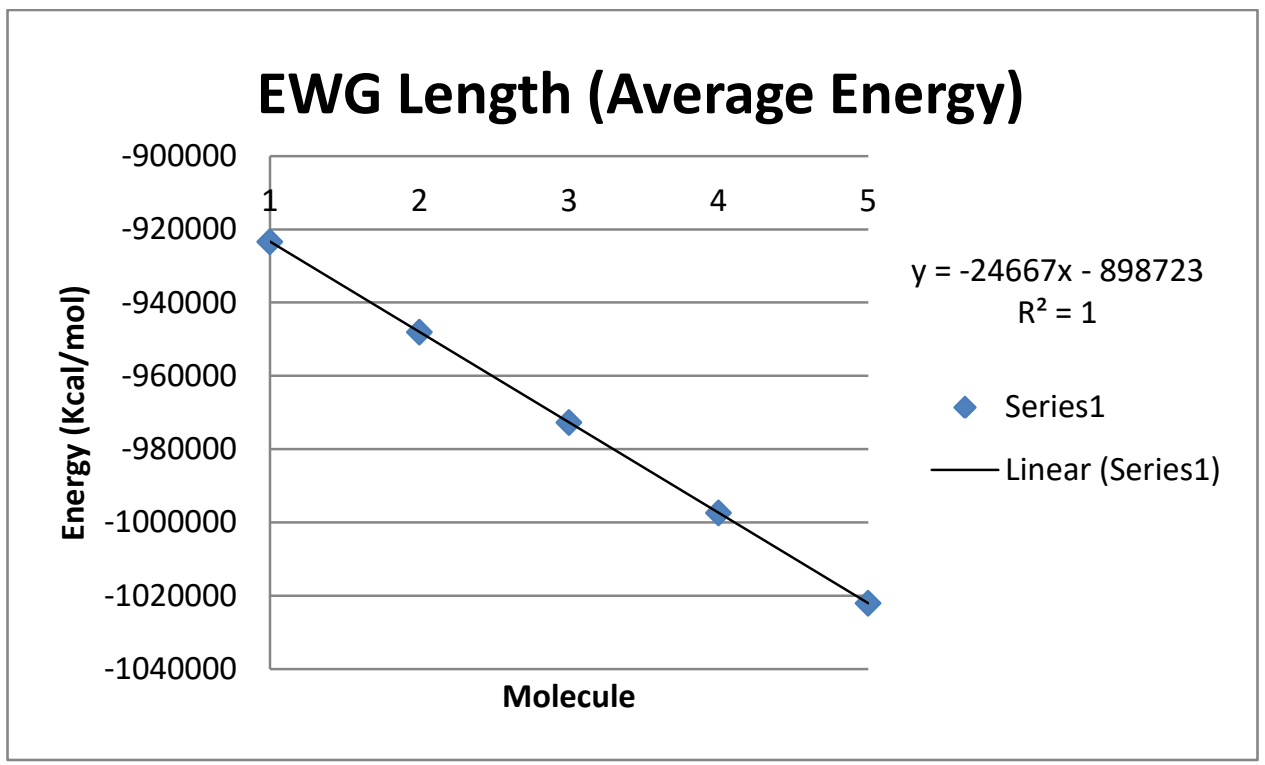


Electron Donor Group (Length)

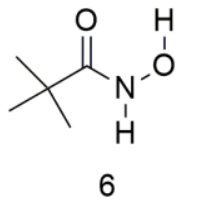<smiles>CC(C)(C)CC(=O)NO</smiles>

7<smiles>CC(C)(C)CCC(=O)NO</smiles>

8<smiles>CC(C)(C)CCCC(=O)NO</smiles>

9<smiles>CC(C)(C)CCCCC(=O)NO</smiles>

10

\begin{tabular}{c|c} 
Molecule & $\Delta \mathrm{G}$ (EDG length) \\
\hline 6 & 19.6297 \\
7 & 11.8935 \\
8 & 11.4005 \\
9 & 11.4146 \\
10 & 11.4298 \\
\multicolumn{2}{c}{ Average 13.154 (3.626) }
\end{tabular}

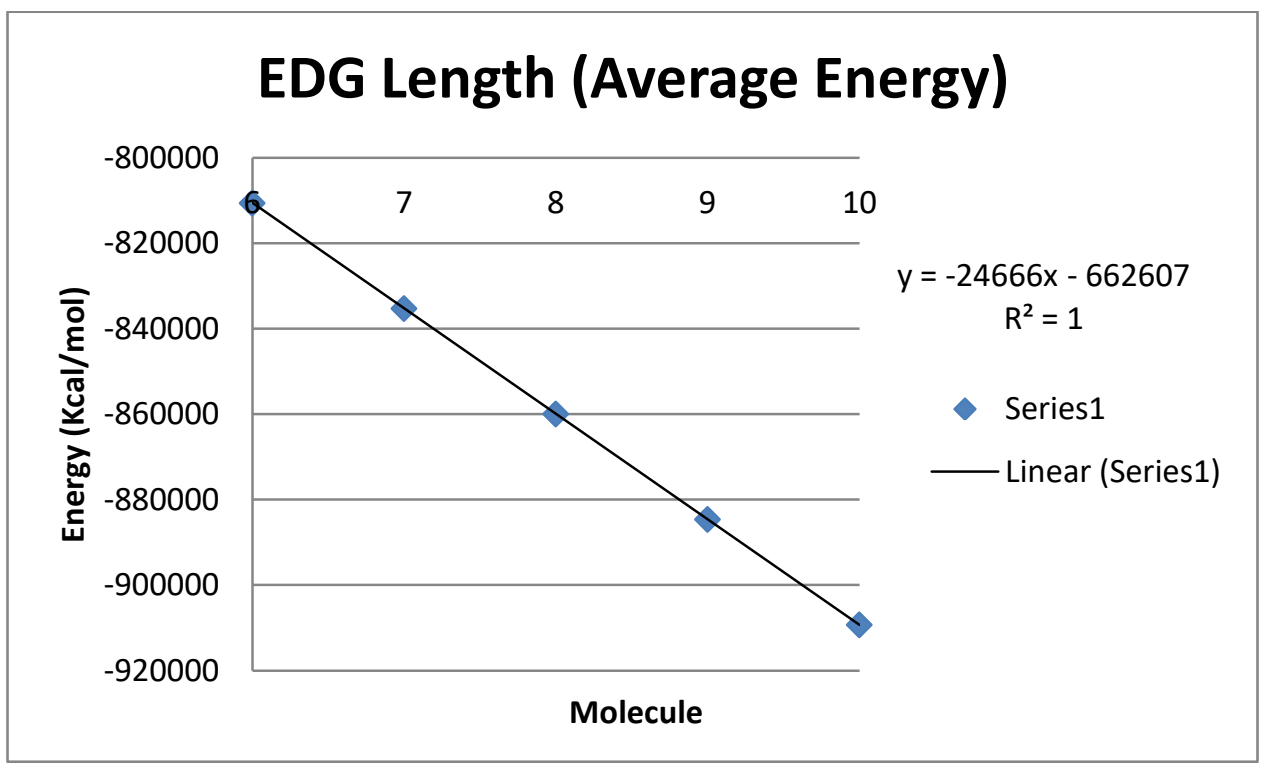




\section{Base Molecule}

$\mathrm{H}_{\substack{\mathrm{N}^{-} \\ \mathrm{H}}}^{\mathrm{O}}$

11

Donors

$\mathrm{H}_{2} \mathrm{~N}_{\substack{1 \\ \mathrm{H}}}^{\stackrel{\mathrm{O}}{\mathrm{O}}}$

12<smiles>CC(C)C(=O)NO</smiles>

16<smiles>O=C(O)NO</smiles>

13<smiles>COC(=O)NO</smiles>

14<smiles>CC(=O)NO</smiles>

15<smiles>CC(=O)NC(=O)NO</smiles>

17

18

\begin{tabular}{c|c} 
Molecule & $\Delta G$ (Donors) \\
\hline 11 & 10.5930 \\
12 & 26.3558 \\
13 & 17.8952 \\
14 & 6.3369 \\
15 & 12.0109 \\
16 & 11.0510 \\
17 & 19.6825 \\
18 & 4402.2620 \\
19 & 2.5601
\end{tabular}

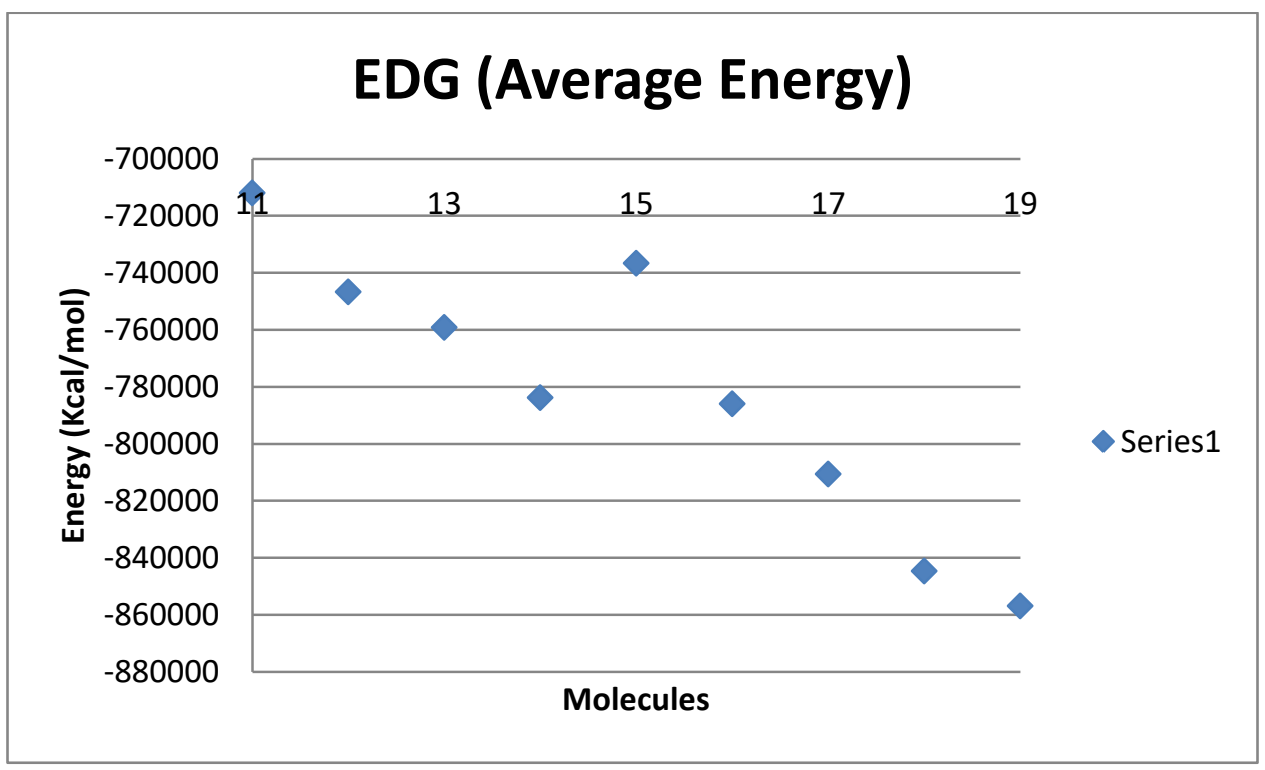




$$
\text { Base Molecule }
$$

Withdrawers

$\prod_{\substack{N^{-} \\ 1}}^{O}$

21

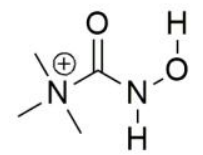

22<smiles>N#CC(=O)NO</smiles>

23
$\prod_{O}^{N_{1}^{-O}} \sum_{N^{\prime}}^{O}$

24
$\mathrm{O}_{2} \mathrm{~N}_{\substack{\mathrm{N} \\ \mathrm{H}}}^{\stackrel{\mathrm{O}}{\mathrm{O}}}$

25<smiles>O=C(O)C(=O)NO</smiles>

26<smiles>COC(=O)C(=O)NO</smiles>

27

\begin{tabular}{c|c} 
Molecule & $\Delta \mathrm{G}$ (Withdrawers) \\
\hline 20 & $\mathbf{1 0 . 5 9 3 0}$ \\
21 & -8.9164 \\
22 & -50.8228 \\
23 & 5.7112 \\
24 & -9.9438 \\
25 & -48.0526 \\
26 & -11.9731 \\
27 & 0.1564
\end{tabular}

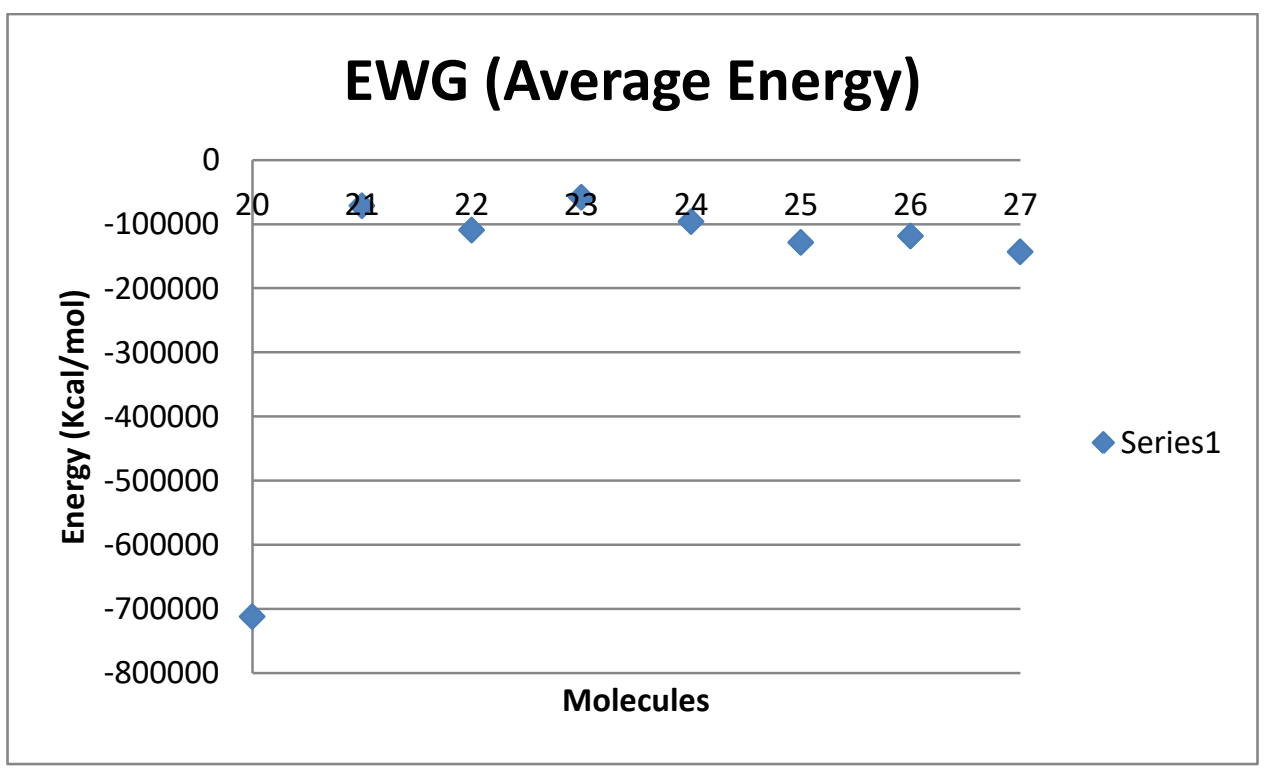




\section{Base Molecule}<smiles>O=CNO</smiles>

28

Halogens<smiles>O=C(F)NO</smiles>

29<smiles>O=C(Cl)NO</smiles>

30<smiles>O=C(Br)NO</smiles>

31<smiles>O=C(I)NO</smiles>

32

\begin{tabular}{c|c} 
Molecule & $\Delta \mathrm{G}$ (Halogens) \\
\hline 28 & $\mathbf{1 0 . 5 9 3 0}$ \\
29 & 8.0303 \\
30 & 10.7065 \\
31 & 9.3601 \\
32 & 5274.5222
\end{tabular}

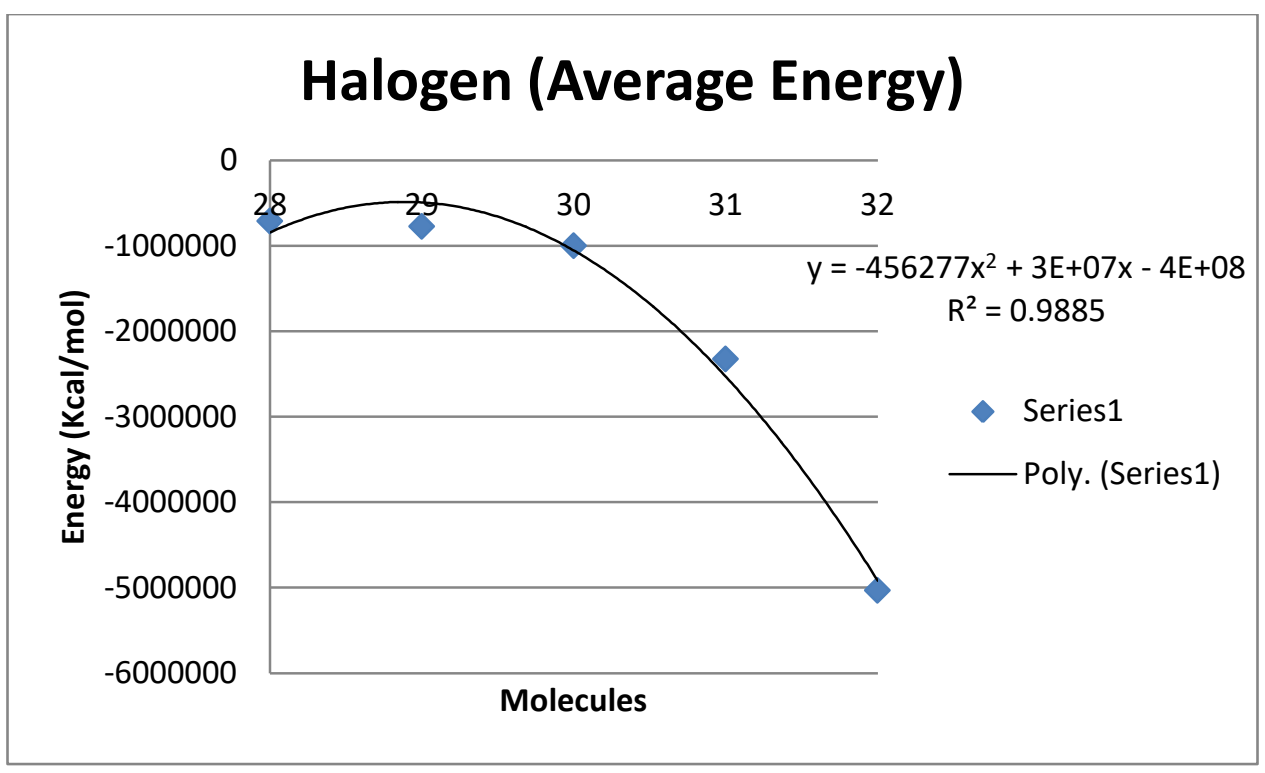


Discussion:

$\Delta \mathrm{G}$ EWG Length

The results indicates that there is a $\Delta G$ difference between the direct binding of an tri-fluoromethane EWG attached to the HXA and a at least one carbon linker of $1 \mathrm{Kcal} / \mathrm{mol}$ with no littler difference thereafter. This indicates that direct binding of the EWG to the HXA has the greatest effect with little linker effect thereafter.

\section{EWG Length (Average Energy)}

The graph of this data shows a linear line with an $R^{2}$ value of 1 . The slope of the line is -24667 with an intercept of -898723 . By using the intercept we are able to calculate the energy of the trifluoromethane of $-898723 \mathrm{Kcal} / \mathrm{mol}$.

\section{$\underline{\Delta G \text { EDG Length }}$}

The results indicates that there is a $\Delta \mathrm{G}$ difference between the direct binding of an tri-methylmethane EDG attached to the HXA and a at least one carbon linker of $8 \mathrm{Kcal} / \mathrm{mol}$ with no littler difference thereafter. This indicates that direct binding of the EDG to the HXA has the greatest effect with little linker effect thereafter. When compared to the EWG difference there seems to be a greater effect when directly attached.

\section{EDG Length (Average Energy)}

The graph of this data shows a linear line with an $R^{2}$ value of 1 . The slope of the line is -24666 with an intercept of -662607 . By using the intercept we are able to calculate the energy of the trimethylmethane of $-662607 \mathrm{Kcal} / \mathrm{mol}$. Using a direct biosteric comparison with the tri-fluoromethane EWG we can see that in this case the EWG was favorable with an insignificant difference in slopes.

\section{$\triangle \mathrm{G} E D G($ Average Energy)}

This data shows a series of electron donating groups directly attached to the HXA to determine the overall $\Delta G$ of the binding of a Zinc (II) ion compared to the standard HXA. The results find a most of the results comparable to the standards energy of 10.5930 . The overall $\Delta G$ energy is not favorable however many are smaller than the standard HXA. Only molecule 18 showed a large difference in the energy of the bound vs unbound states. No rational reason was found and this molecule will be studies further.

\section{EDG (Average Energy)}

The graph of this data shows a series of 8 molecules which maintains electron donating groups directly attached to the HXA when compared to the standard HXA however all molecules are unfavorable. The data finds the average energy of EDG slightly lower than the control indicating more stable molecules when compared to the standard. All of the 8 molecules are lower energy than the standard molecule indicating increased stability. The most stable EDF group is the addition of a phenyl group to the HXA moiety. Future research will look at molecule 19. 


\section{$\Delta \mathrm{G}$ EWG (Average Energy)}

This data shows a series of electron withdrawing groups directly attached to the HXA to determine the overall $\Delta G$ of the binding of a Zinc (II) ion compared to the standard HXA. The results find a most of the results comparable to the standards energy of 10.5930. Molecules 21, 22, 24, 25, and 26 were found to be favorable when compared to the standard.

\section{EWG (Average Energy)}

The graph of this data shows a series of 7 molecules which maintains electron withdrawing groups directly attached to the HXA when compared to the standard HXA. The data finds the average energy of EWG significantly higher than the control indicating less stable molecules when compared to the standard.

\section{$\underline{\Delta G \text { Halogens }}$}

This data shows a series of halogens directly attached to the HXA to determine the overall $\Delta G$ of the binding of a Zinc (II) ion compared to the standard HXA. The results find a large difference between molecules 28 - 31 and 32 the iodo attached molecules. The difference between the iodo-bound and iodo-apo molecules is highly unfavorable.

\section{Halogens (Average Energy)}

The graph of this data shows a series of 4 halogen attached molecules when compared to the standard HXA. The data finds the average energy of halogen significantly lower with a second order polynomial line fit with an $R^{2}$ value of 0.9885 . This indicates that as the size of the halogen attachment increases the energy becomes significantly smaller.

\section{Conclusion:}

This study indicates a trend that EDG are the best molecules to use to increase the stability of the HXA. These EDG have to be bound directly to the HXA with linkers showing little to no difference in binding energy. The best binding molecule was a phenyl attached HXA. The halogen student found the larger the size the more stable the molecule with the iodo being the most stable. 